\title{
Implementation of Dijkstra's Algorithm in the Shortest Route
}

\author{
Wawan Gunawan ${ }^{1 *}$, Susafa'ati ${ }^{2}$, Budi Sudrajat ${ }^{3}$ \\ ${ }^{1}$ Faculty of Computer Science, Universitas Mercu Buana \\ ${ }^{2}$ Informatics, STMIK Nusa Mandiri \\ ${ }^{3}$ Faculty of Information Technology, Universitas Bina Sarana Informatika
}

DOI: $10.36348 /$ SB.2019.v05i12.001

| Received: 20.11.2019 | Accepted: 27.11.2019 | Published: 10.12.2019

*Corresponding author: Wawan Gunawan

Email: wawan.gunawan@mercubuana.ac.id

\section{Abstract}

Efficient travel in terms of distance, time and cost are the needs of every traveler. Not all travelers always make careful planning before going on a trip and it could be that the trip is done unexpectedly. In order to help travelers to get a wellplanned trip, technological utilization is needed so that travelers can easily get the shortest distance on the route. Smaller distances can optimize usage costs and possibly travel time. One of them is the creation of the website-based shortest route search destination search application with a mobile friendly display. The dijkstra algorithm is one of the algorithms for determining the shortest route from one tourist attraction to another. The calculation of the dijkstra algorithm begins with determining the node (point) that will be formed into a graph.

Keywords: Travel, Shortest Route, Dijkstra's Algorithm, Beta Testing.

Copyright @ 2019: This is an open-access article distributed under the terms of the Creative Commons Attribution license which permits unrestricted use, distribution, and reproduction in any medium for non-commercial use (NonCommercial, or CC-BY-NC) provided the original author and source are credited.

\section{INTRODUCTION}

The development of information technology has resulted in the availability of a variety of geographical information services that provide information about the location, route, mileage and even to the level of density of certain lines [1]. But in its implementation of the needs of travelers still have some problems, such as the difficulty of determining the distance to reach the location that can be reached [2]. In addition, the main problem has to determine the travel route manually so that it consumes less than optimal time [3]. The results of determining the shortest route will be taken into consideration in making a decision to show the route.

Traveling Salesman Problem is a concept that is in accordance with the problems that are being experienced in determining the route of travel. Basically the TSP concept is that a traveling salesman is required to visit every city included in his territory and then return to the starting point with the shortest distance. This case will visit all the destination locations determined through the shortest potential route without repeating the same location path and finally returning to the original location [4].
Dijkstra's algorithm is a well-known algorithm for finding the shortest path applied to directed and weighted graphs to solve from one point to another point and also from point one to all points [5]. This algorithm has been widely used in determining the shortest distance between two points.

Based on the identification of the problems that have been described, it can be formulated how to design and build a system for making efficient travel plans, especially in terms of mileage using the dijkstra algorithm?. While the objectives and benefits to be gained (1) represent the results of the google maps feature in helping provide user directions, (2) produce the shortest route that can be used by users so as to produce an efficient travel plan.

\section{REVIEW OF LITERATURE Application}

Applications according to Kamus Besar Bahasa Indonesia are computer programs or software designed to do certain tasks. While computer programs are programs that are created specifically to allow computers to perform certain functions [6]. 


\section{Algoritma Dijkstra}

Algorithms are effective methods that are expressed as a limited circuit. An algorithm is also a collection of commands to solve a problem [7].

Understanding the algorithm is a logical and systematic arrangement to solve a problem or to achieve certain goals. In the computer world, algorithms play an important role in the development of software, in everyday life that is possible without our knowing that algorithms have entered our lives [7].

"Dijkstra's algorithm is often known as single source shortest path algorithm. Dijkstra algorithm used the method of increasing node by node to get a shortest path tree which makes the starting point as its root [8]".

"Dijkstra's algorithm can be implemented to find the shortest one routes from tourists to other tourist locations. That The weakness found in this application is the Dijkstra algorithm. Will calculate the specified area, so if there is a new undefined area like vertices and graphs, the algorithm can't work like that must [9]".

\section{Shortest path}

Shortest path problem is the problem of finding a path (one-to-one) or more from the initial node to the end node based on the smallest weight [10]. From the results of its application it can be used as a guide to the route that must be taken to get the shortest distance or can solve the problem that is described by a graph, robotics, transportation and others.

The search for the shortest route (shortest path problem) in a graph as an optimization effort to get the route with the smallest weight. This effort is often found in a weighted-connected graph [11].

\section{RESEARCH METHODS}

\section{Data Collection Method}

The data collection method used in this study is:

Observation Method. Observation or direct observation of the object of research. The observation technique is carried out by structured observation by preparing a list of data and data source needs.
Literature review method. Methods of collecting data obtained by studying, researching, and reading books, information from the internet, journals, theses, and theses related to dijkstra algorithm applications and implementation.

\section{Software Development Life Cycle}

Software development for implementation in this study uses the System Development Life Cycle (SDLC) method which in developing eXtreme Programming system has four stages in the process, namely;

\section{Planning}

Planning or designing software that will be built to achieve the goals that have been determined with an activity to collect the needs of data that has been collected by observation, and interviews with researchers.

2. Design

Designing system modeling using the Unified Model Language after drawing conclusions from data and analysis.

3. Coding

Begin to write program code using various programming languages and link it to the database.

4. Testing

Conduct a trial of the program created and check the running of the functions that exist in the application.

\section{Design System}

UML (Unified Modeling language) is one standard language that is widely used in the world industry to define requirements, make analysts and design, and describe architecture in object oriented programming.

The design of this application uses UML (Unified Modeling Language) which consists from the design of use case diagrams, to design activity diagram, and diagram design sequence.

\section{Use Case Diagram}

Use case diagram of the shortest route search route has 2 (two) actors are user and admin.

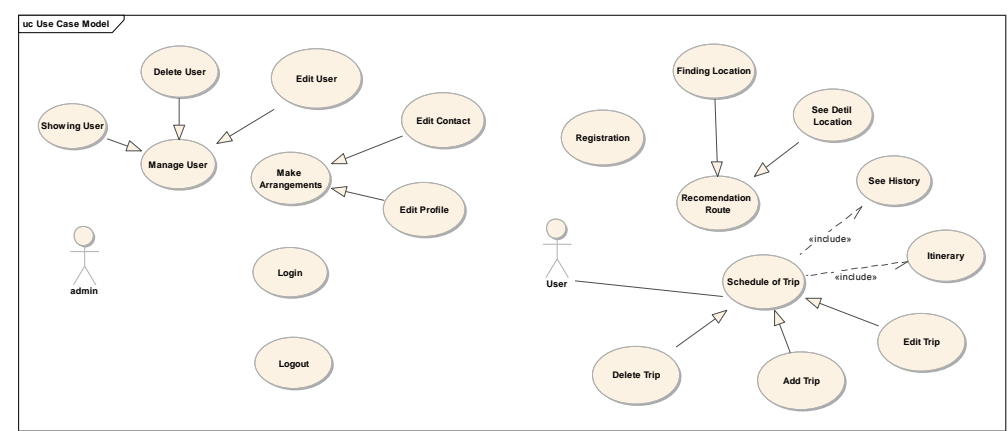

Fig-1: Use Case Diagram 


\section{Activity Diagram}

Activity diagrams illustrate the various activities flow in the system being built and how each flow starts, the decisions that might occur and how the flow ends.
The following is a diagram of the activities of the registration process consisting of two business organizations that are shown on Fig. 2(a) and sign-in applications that can be described as images on Fig. 2(b).

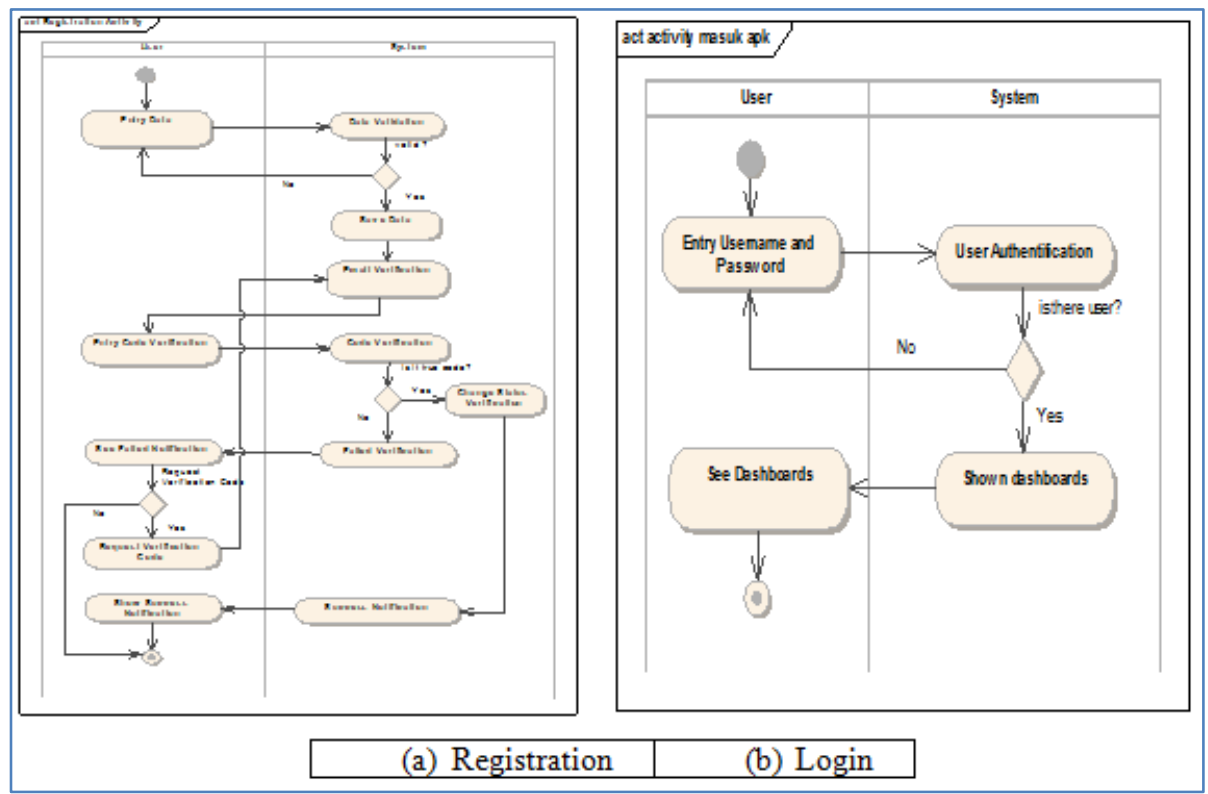

Fig-2: Activity Diagram (a)(b)

User management has three features that will be described in detail through activity diagrams with user management that can only be done by the admin. Figure 3(a) is an activity diagram that explains the activity process of seeing user details, while the activity of changing user data can be seen in Figure 3(b). Another user management feature is to delete user accounts from the application with the activity steps depicted in Figure 4.

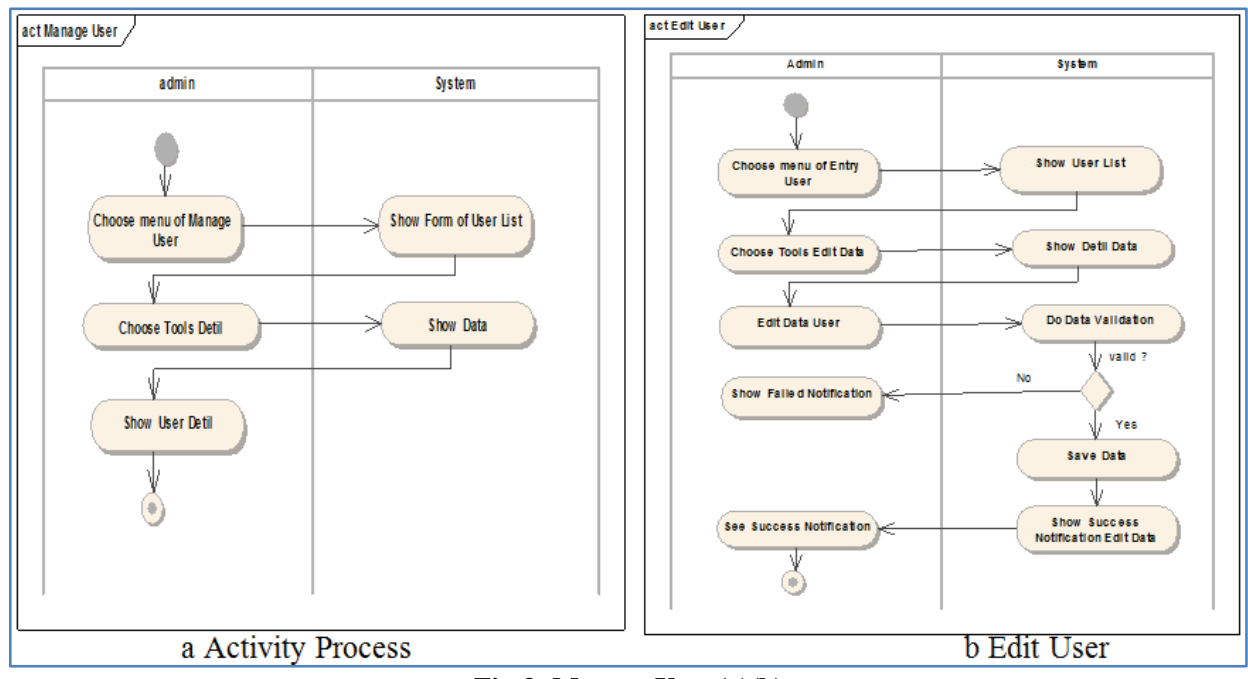

Fig-3: Manage User (a)(b) 


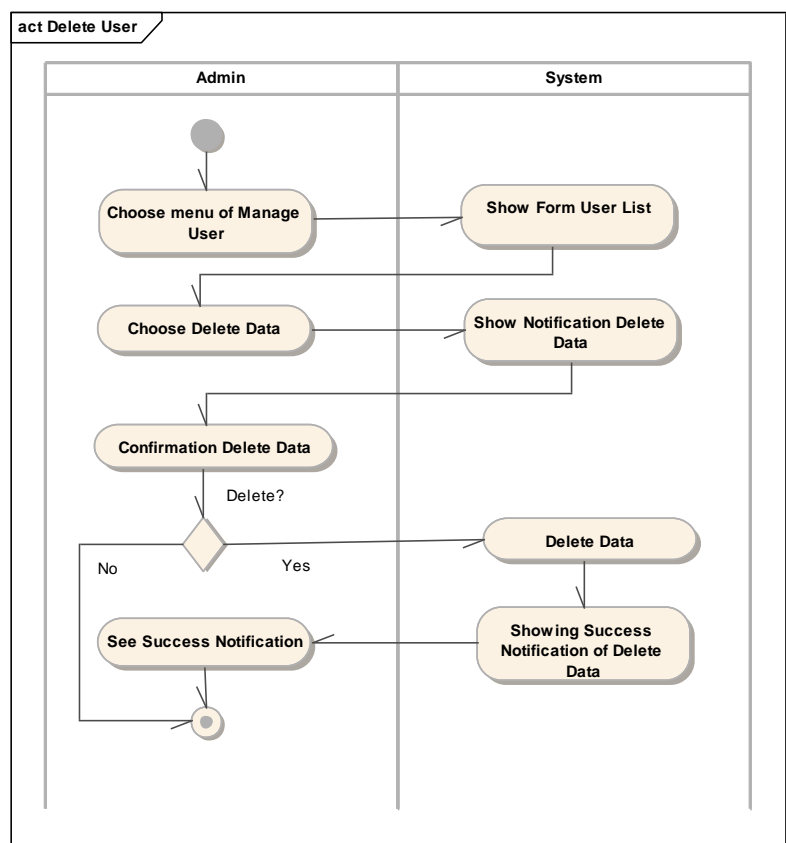

\section{Sequence Diagram}

Sequence diagram describe interactions between objects in and around the system. In the Sequence diagram illustrates a series of steps performed on the system in response to a process to produce certain outputs.
Following is the Sequence diagram found in the shortest route destination search application. In this Activity Diagram, describe the registration process in the on figure 5(a) system and explain the application entry and validation of users on figure $5(b)$.

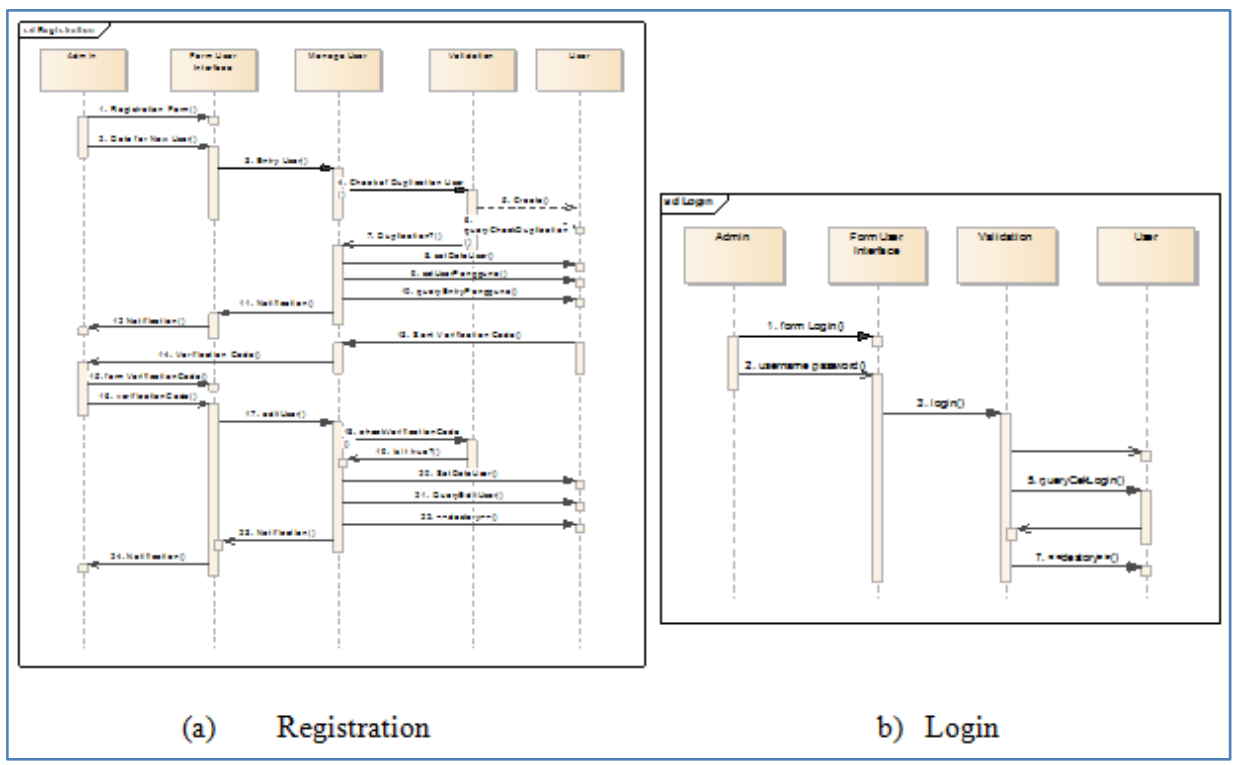

Fig-5: Registration and Login (a)(b)

The user management module has features that can only be accessed by the admin, including making changes to the user's data and status, and removing users from the application. Figure 6 is an overview of the process of seeing detailed data, changing data (a) and looking at user status. While deleting a user will only delete the user's account, where travel plans that have been made will still be stored in the system. The process of erasing user data in the system can be seen on figure (b).

Itinerary is the main feature of the application that serves to provide recommendations for optimal travel route order for users. This module has three features namely making a new trip, changing travel plans and deleting travel plans. In Figure 7 illustrates the system process in making a new journey. 


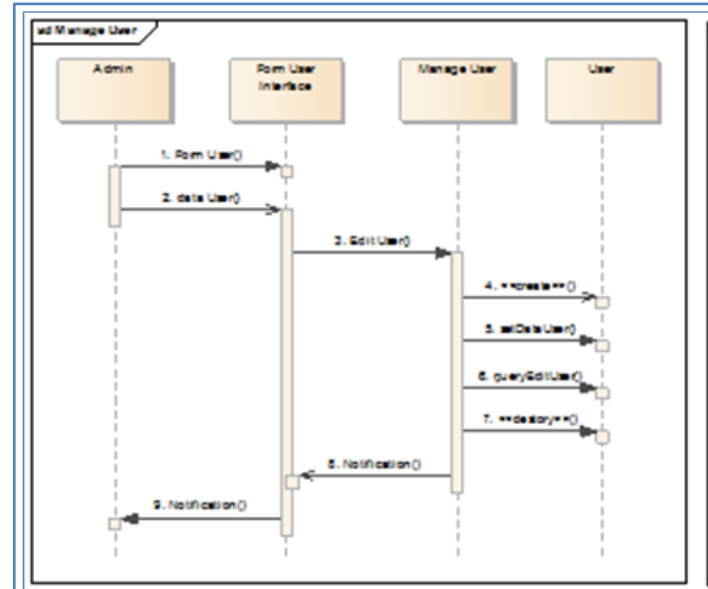

(a)

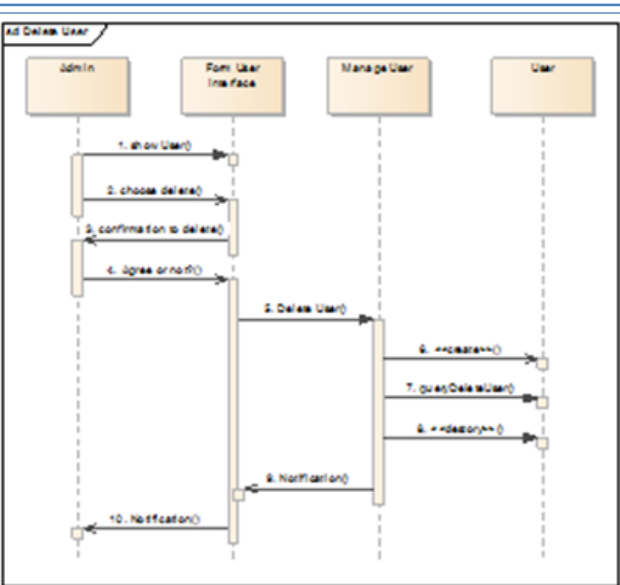

(b) Delete Data

Fig-6: Sequence Manage Data

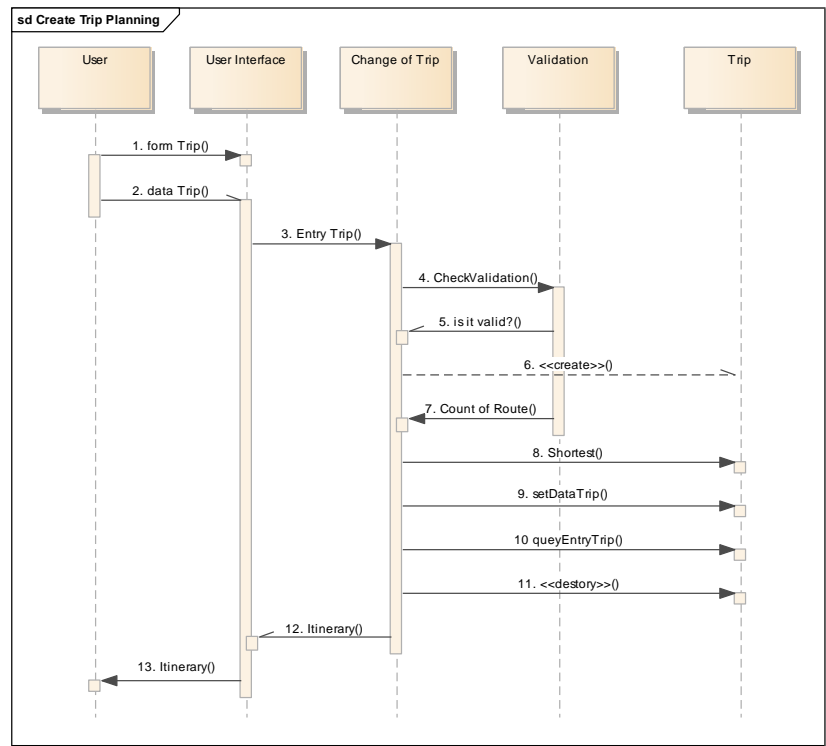

Fig-7: Sequence of Create Journey

\section{RESULT AND DISCUSSION}

\section{Dijkstra Algorithm}

This algorithm will finding shortest route from node a to node $b$.

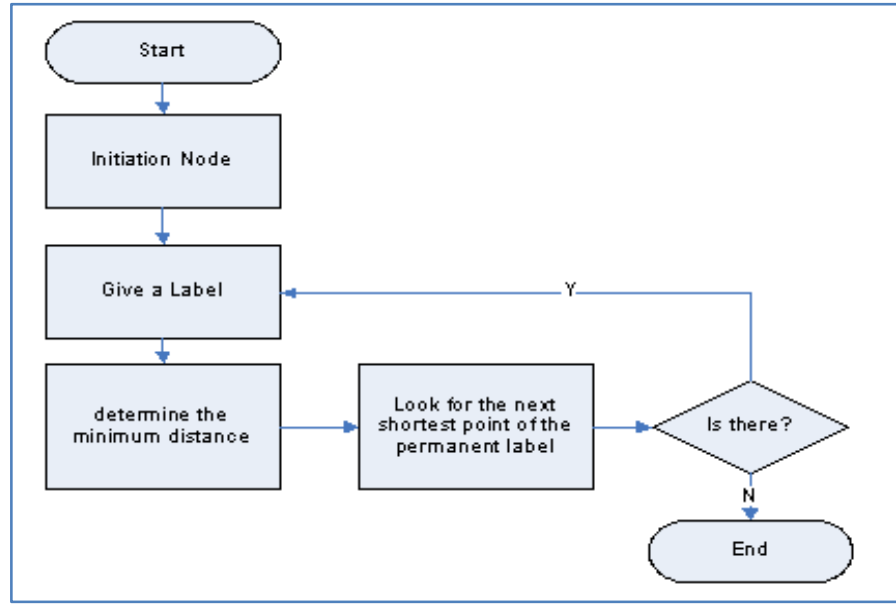

Fig-8: Flowchart Dijkstra Algorithm 


\section{User Interface}

The user must first register which can be seen in figure 9(a), after registered the user enters the application by entering the username and password through the login page as is shown on figure $9(b)$. The home page design and menu list of the application in the sidebar is show on figure 9(c), and users can change profiles through the profile settings feature with a display like is show on figure $9(\mathrm{~d})$.

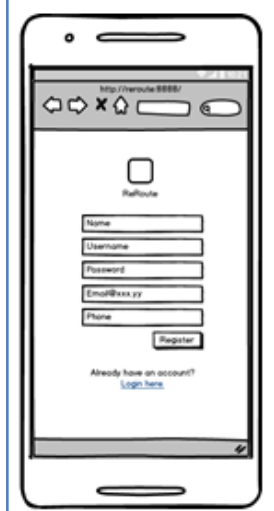

(a) Registration

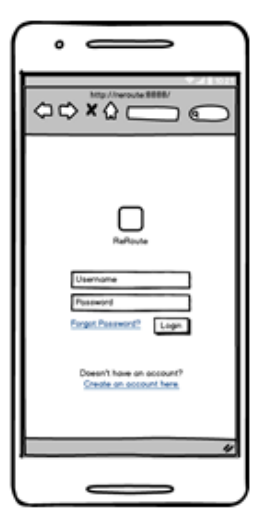

(b) Login

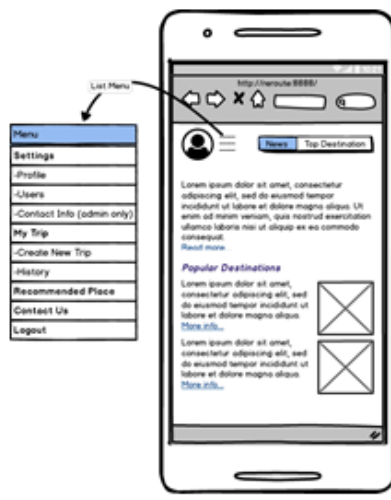

(c) Sidebar

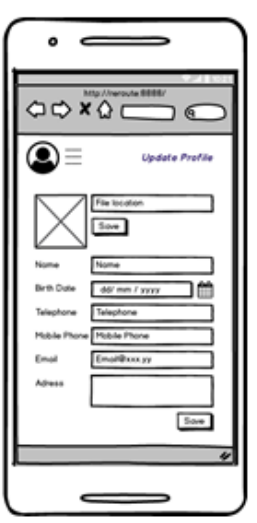

(d) Profile

Fig-9: User Interface Application

Figure 10(a) is a travel plan page design carried out in three stages to obtain the shortest route calculation results. While the itinerary page interface design is the result of route calculation in the form of a map of the direction of travel to arrive at the destination depicted in Figure 10(b).

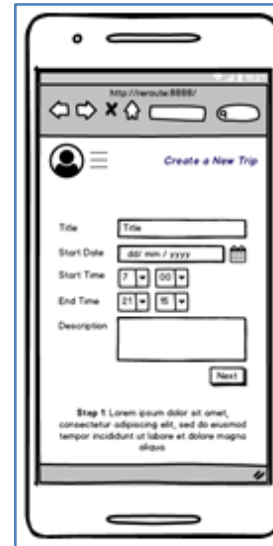

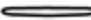

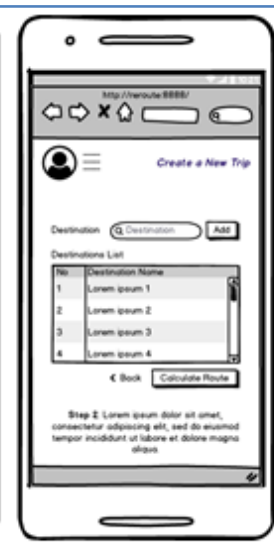

(a) Travel Plan

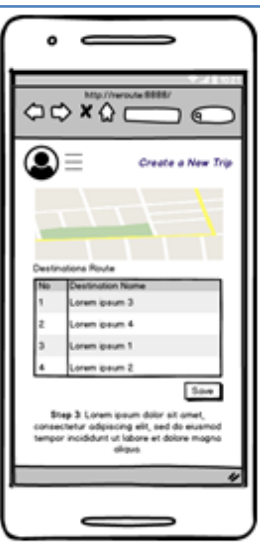

Fig-10: Travel Plan and Itinerary

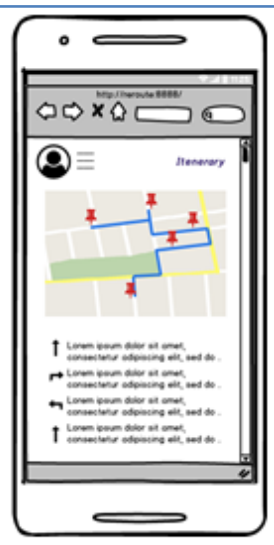

(b) Itinerary

\section{Implementation}

The user registers through the Sign Up menu by requiring to fill in their name, telephone number, email address and application password as shown in figure 11(a). After completing registration, the application will send verification to the registered email to ensure the email address is correct and the new account is ready to use. The main page displayed on the sign in page is shown in Figure 11(b). Users can make travel plans if they are already registered and sign in to the application. 


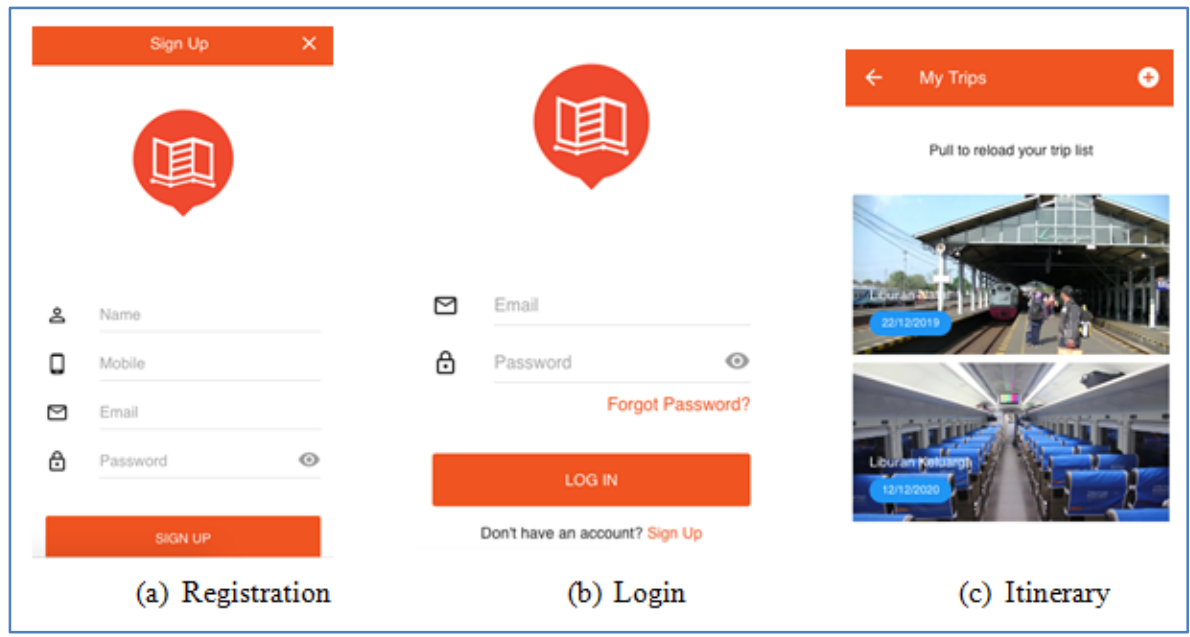

Fig-11: Implementation System

In the itinerary menu, the user will first see a history of the itinerary that has been made, whether it has been done or a plan on a future date as shown in figure $11(\mathrm{c})$. Creating a new itinerary can be done by selecting the plus button on the top right of the menu, then selecting the start and end hours of the trip, as well as the destination destinations (at least 6 places) as shown in figure 12. Each selected destination will be displayed detailed information starting from the map point, address, operating hours; the information is synchronized from google maps as shown in figure 13.

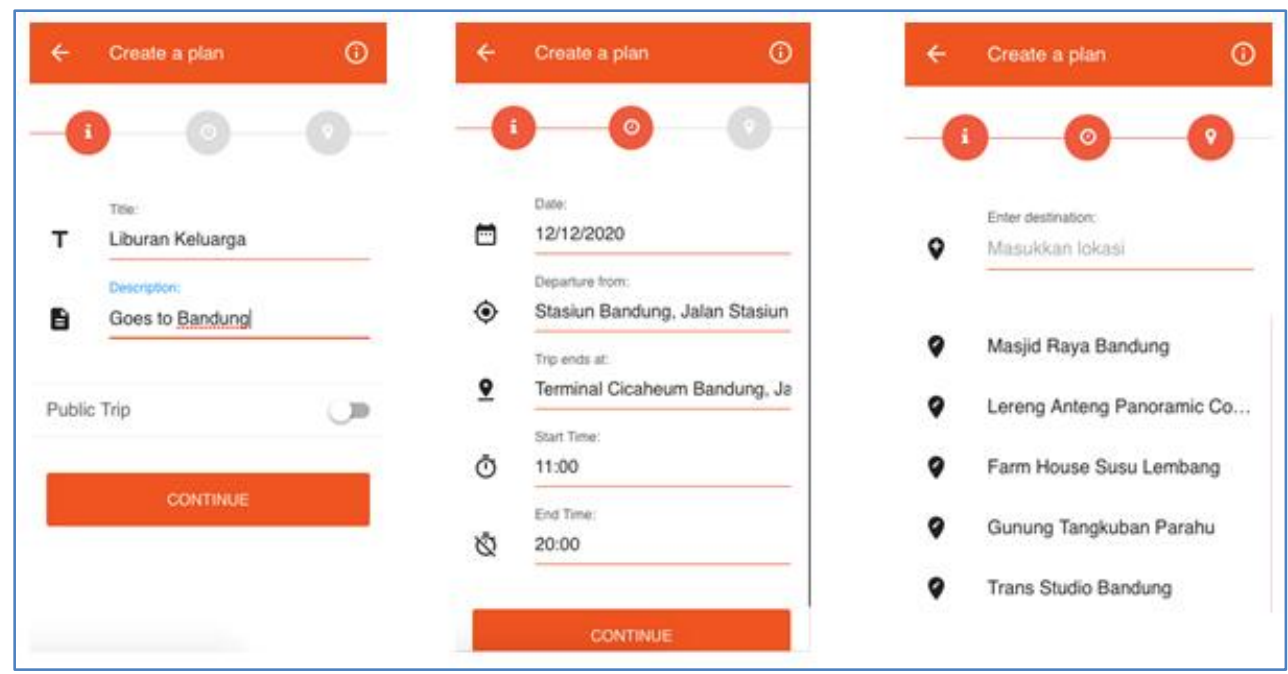

Fig-12: Implementation Create Journey Plan 


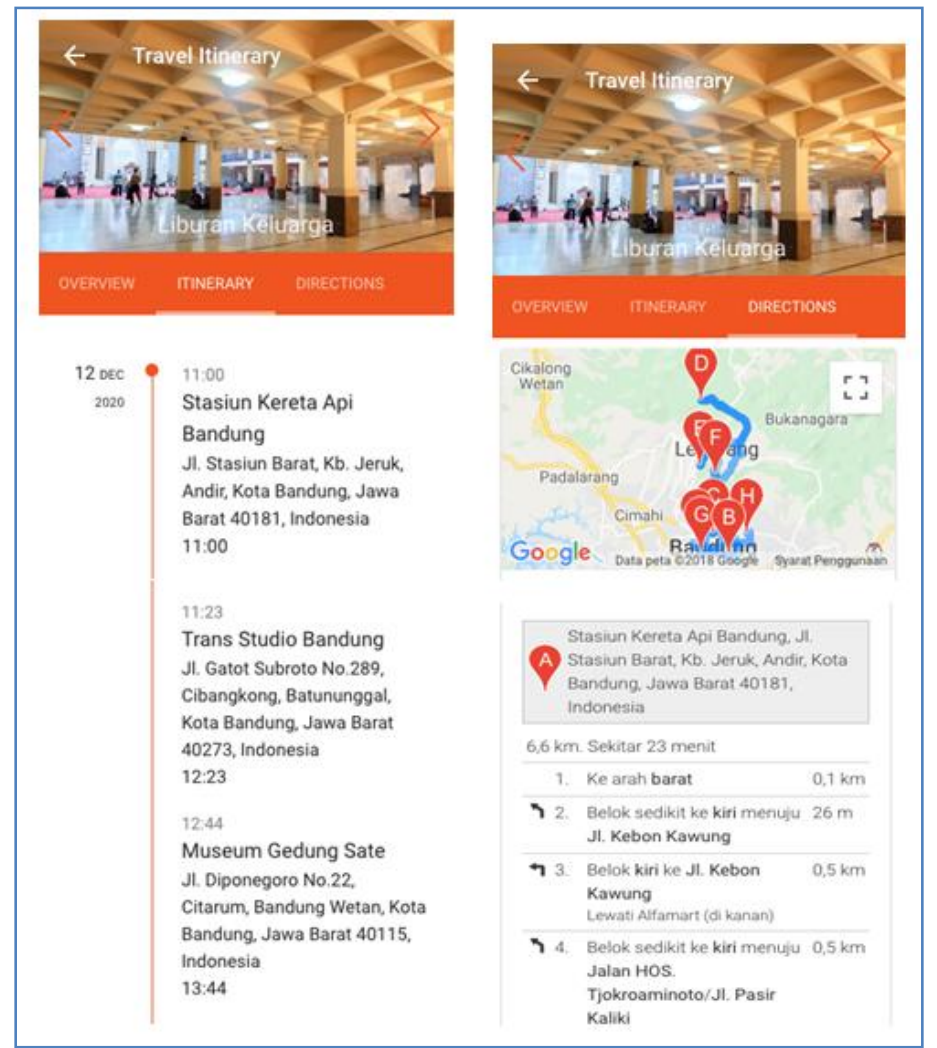

Fig-12: Implementation of Itinerary

\section{CONCLUSION}

As a conclusion from this research can be presented as follows:

- One way to make it easier for travelers to get efficient travel plans is to implement the dijkstra algorithm in a location search application.

- In implementing the dijkstra algorithm, as a distance calculator from the initial location of the tourist destination to the final location of the tourist destination without repeating other tourist destinations. Dijkstra will calculate each of the shortest distances from each point or destination object from the initial location to the final location of the tourist attraction. Dijkstra stores every smallest value at each distance from each point until it gets the shortest total distance.

- From beta testing through the questionnaire, it was concluded that in addition to calculating the shortest route based on distance, users also expect calculations based on traffic and road conditions.

- The results integrate the shortest route search application with dynamic maps from the Google maps API and other APIs so that they get location information and updated route conditions.

\section{SUGGESTION}

For improvement and to improve better results, it is recommended for further research:

- Extending the application features is not only based on mileage but also pay attention to traffic conditions.
- Seeing the lack of dijkstra algorithm where the algorithm is only limited between objects, it is recommended that further research can develop a system that can optimize the dijkstra algorithm perfectly.

\section{ACKNOWLEDGEMENT}

Praise be to the presence of Allah S.W.T. who has given His mercy so that the writing of this scientific article is resolved. And I do not forget to say thank you to the extended family of the Faculty of Computer Science, Universitas Mercu Buana, who has provided support in writing this scientific article.

\section{REFFERENCE}

1. Ashokkumar, P., Arunkumar, N., \& Don, S. (2018). Intelligent optimal route recommendation among heterogeneous objects with keywords. Computers \& Electrical Engineering, 68, 526-535.

2. Chládek, P., \& Smetanová, D. (2018). Travelling Salesman Problem Applied to Black Sea Ports used by Czech Ocean Shipping Companies. NAŠE MORE: znanstveno-stručni časopis za more $i$ pomorstvo, 65(3), 141-145.

3. Dzulfikar, M. Z., Lhaksamana, K. M., \& Baizal, Z. K. A. (2017). Penerapan Algoritma Artificial Immune System Untuk Penyusunan Rencana Perjalanan Pariwisata. eProceedings of Engineering, 4(2). 
Wawan Gunawan et al., Sch Bull, Dec 2019; 5(12): 681-689

4. Chen, X., Zhou, Y., Tang, Z., \& Luo, Q. (2017). A hybrid algorithm combining glowworm swarm optimization and complete 2-opt algorithm for spherical travelling salesman problems. Applied Soft Computing, 58, 104-114.

5. Sedeno-Noda, A., \& Raith, A. (2015). A Dijkstralike method computing all extreme supported nondominated solutions of the biobjective shortest path problem. Computers \& Operations Research, 57, 83-94.

6. Depdiknas, R. I. (2003). Departemen Pendidikan Nasional Republik Indonesia.

7. Maulana, G. G. (2017). Pembelajaran Dasar Algoritma dan Pemrograman Menggunakan Elgoritma Berbasis Web. Jurnal Teknik Mesin Mercu Buana, 6(2), 69-73.
8. Patel, V., \& Bagar, C. (2014). A survey paper of Bellman-Ford algorithm and Dijkstra algorithm for finding shortest path in GIS application. International Journal of P2P Network Trends and Technology, 5, 1-4.

9. Nugroho, A., \& Afandi, R. T. (2018). Application of Broadcast Position Android-Based Tourist Group Using Google API. Int J Comput Neural Eng, 5(1), 98-104.

10. Duque, D., Lozano, L., \& Medaglia, A. L. (2015). An exact method for the biobjective shortest path problem for large-scale road networks. European Journal of Operational Research, 242(3), 788-797.

11. Zhu, S., \& Levinson, D. (2015). Do people use the shortest path? An empirical test of Wardrop's first principle. PloS one, 10(8), e0134322. 